\title{
Determinan Kepatuhan Ibu Hamil dalam Mengkonsumsi Obat selama Kehamilan
}

\author{
Islah Wahyuni, Linda Suryani \\ Email: islah_fattan@yahoo.co.id \\ Prodi Sarjana Kebidanan dan Profesi Bidan, Stikes Payung Negeri Pekanbaru, Indonesia \\ Jalan Tamtama No.6 Kelurahan Labuh Baru Kecamatan Payung Sekaki Pekanbaru Riau
}

\begin{abstract}
Abstrak
Penggunaan obat-obatan selama kehamilan bertujuan untuk meningkatkan kesehatan ibu dan janin. Pemberiannya haruslah disesuaikan dengan kebutuhan ibu dan harus dalam pengawasan tenaga kesehatan. Kepatuhan ibu dalam mengkonsumsi obat-obat selama masa kehamilan dipengaruhi oleh beberapa faktor, seperti pengetahuan, sikap, penjelasan cara pakai obat dari tenaga kesehatan, persepsi dan pengalaman dan lainnya. Tujuan penelitian untuk mengidentifikasi Determinan Kepatuhan Ibu Hamil Dalam Mengkonsumsi Obat Selama Kehamilan. Sampel penelitian sebanyak 54 responden adalah ibu hamil sejak Maret - Mei 2021. Hasil penelitian didapatkan hasil 29 responden $(53,7 \%)$ patuh dalam mengkonsumsi obat dalam kehamilan, berdasarkan faktor penjelasan nakes mayoritas lengkap yaitu 34 orang $(79,1 \%)$, berdasarkan Pengetahuan mayoritas baik yaitu 35 orang (72,9\%). Berdasarkan sikap mayoritas positif yaitu 44 orang (68,8\%), berdasarkan Kecemasan terhadap efek samping obat mayoritas ada yaitu 33 orang (68,8\%), berdasarkan frekuensi kunjungan ANC mayoritas rutin $(\geq 4 \mathrm{x})$ yaitu 32 orang (59,2\%). Diharapkan agar ibu hamil dapat memperhatikan aturan dan tata cara mengkonsumsi obat selama kehamilan ini.
\end{abstract}

Kata kunci: kepatuhan; konsumsi obat; kehamilan.

\begin{abstract}
The use of drugs during pregnancy aims to improve the health of the mother and fetus. The provision must be adjusted to the needs of the mother and must be under the supervision of health workers. Maternal compliance in taking drugs during pregnancy is influenced by several factors, such as knowledge, attitudes, explanations of how to use drugs from health workers, perceptions and experiences and others. The purpose of the study was to identify the determinants of compliance of pregnant women in consuming drugs during pregnancy. The research sample was 54 respondents who were pregnant women from March to May 2021. The results showed that 29 respondents $(53.7 \%)$ were obedient in taking drugs during pregnancy, based on the explanation of the majority of health workers, namely 34 people $(79.1 \%)$, The majority of knowledge is good, namely 35 people $(72.9 \%)$. Based on the attitude of the majority positive, namely 44 people $(68.8 \%)$, based on anxiety about drug side effects the majority were 33 people $(68.8 \%)$, based on the frequency of routine ANC visits $(\geq 4 \mathrm{x})$ namely 32 people $(59.2 \%)$. It is hoped that pregnant women can pay attention to the rules and procedures for taking drugs during this pregnancy.
\end{abstract}

Keywords: compliance; drug consumption; pregnancy. 
Jurnal Kebidanan Harapan Ibu Pekalongan

\section{Pendahuluan}

Penggunaan obat-obatan

kimiawi selama kehamilan sangat dibatasi dikarenakan efek samping yang tidak diharapkan[1].Kehamilan merupakan suatu periode yang berbeda dari seorang perempuan, akibat adanya banyak perubahan dalam tubuh atau fisiknyasehingga juga mempengaruhi proses farmakokinetik dan farmakodinamik obat yang masuk kedalam tubuhnya[2]. Peningkatan $p H$ lambung dan penurunan motilitas usus juga merubah volume distribusi penyebaran obat, mengganggu aktivitas penyerapan atau kecepatan obat. Jumlah plasma darah ibu meningkat sehingga menjadikan proses distribusi obat dalam pembuluh darah juga berubah, serta penambahan kadarestrogen dan estrogen akan mempengaruhi metabolisme obat dihati dan laju filtrasi glomerulus di ginjal juga akan meningkat. Plasenta sebagai alat pertukaran nutrisi dan obatobatan akan membawa semuanya ke janin. Oleh karena itu obat-obat yang diberikan akan dapat mempengaruhi pertumbuhan janin. Seperti efek teratogenik, keguguran, Untuk itu perlu diperhatikan aturan pakai dan meminimalkan risiko obat bagi ibu dan janin selama kehamilan[3].

Obat yang dikonsumsi oleh ibu selama hamil sangat dibatasi dan hanya bersifat menunjang kesehatan ibu selama hamil, serta obat yang bersifat symptomatik mengatasi gelaja gangguan fisik pada ibu seperti mual muntah, demam, sakit kepala, nyeri gigi, batuk pilek, dan lain-lain[4]. Tingkat keamanan obat menjadi keharusan yang mesti diperhatikan oleh seorang tenaga kesehatan saat memberikan terapi obat-obatan kepada ibu hamil[5].
Sejak awal kehamilan, ibu sudah mengalami keluhan fisik seperti mual muntah, Hiper Emesis Gravidarum, pusing dan mudah capek, perdarahan dan keguguran mengancam bahkan bisa sampai Anemia[6]. Belum lagi saat hamil berlanjut ibu mulai merasakan nyeri pinggang, sakit kepala, kram otot, dan tentunya kebutuhan nutrisi dan suplemen vitamin mineral akan semakin meningkat, agar pertumbuhan janinnya selalu baik. Kondisi ini tentunya membutuhkan terapi farmakologik pada ibu hamil dalam membantu mensupport memulihkan kondisi kesehatannya selama kehamilan ini[3].

Terapi farmakologik dipercaya akan meningkatkan kemampuan ibu dalam menstimulasi sel-sel jaringan tubuh untuk meregenerasi sel dan memperbaiki sel yang sudah rusak, serta membantu kerja organ untuk mengatasi keluhan-keluhan yang berakibat komplikasi yang fatal bagi janin dan kehamilan ibu. Standar pemberian obat tentunya yang memenuhi level keamanan yang tepat bagi ibu hamil. Hal ini mengindikasikan bahwa obat tidak menimbulkan adverse side reaction (ASR) bagi janin yang sedang dikandung[7].

Pemberian obat selama kehamilan bermanfaat memenuhi kebutuhan suplemen vitamin mineral yang tinggi selama kehamilan yang tidak didapatkan secara penuh dari asupan makanan sehari-hari, angka kecukupan nilai gizi yang tidak memenuhi kebutuhan harian dan rendah mengakibatkan ibu akan mengalami keluhan-keluhan lazim yang biasa terjadi pada masa kehamilan seperti gangguan fisik mual, muntah, pusing, kram otot, nyeri pinggang, hingga anemia, namun hal ini tetap 
menjadi perhatian yang tidak dapat diindahkan[3].

Pemberian obat pada ibu hamil sehat biasanya mengacu pada usia kehamilan dan keluhan yang dialaminya, dimana saat berada di trimester I pemberian terapi farmakologiknya untuk mengatasi mual dan muntah seperti: vitamin B6, metocloropramid, Ondansetron. Untuk vitamin dan mineral: asam folat, calcium, vitamin $\mathrm{C}$, vitamin BComplek[8]. Pada trimester lanjut, biasanya pemberian obat lebih fleksibel dan fokus pada pencegahan Anemia, menstabilkan tekanan darah dan meningkatkan kebutuhan calcium ibu, maka terapi farmakologik yang sering diberikan adalah: Calsium lactas, Tablet Sulfas Ferrosus, Vitamin C[4].

Pada kenyataannya dilapangan sering ibu hamil mendapatkan pemahaman dan penjelasan yang kurang baik dalam menggunakan obat selama kehamilan, sehingga mempengaruhi kepatuhan mereka dalam mengkonsumsi obat yang diberikan kepada mereka[9]. Kurangnya penekanan bahwa obat mesti dihabiskan dan mesti ditambah kembali oleh ibu hamil saat obatnya habis, menjadikan ibu hamil kurang aware dan tidak mendapatkan tambahan suplemen vitamin mineral pada setiap bulannya[10][11].

Kepatuhan dalam memgkonsumsi obat-obatan dapat diartikan sebagai suatu bentuk perilaku penderita dalam mengikuti anjuran, instruksi tenaga medis untuk meminum obat yang diberikan. Kepatuhan ibu hamil dalam mengkonsumsi obat-obatan dalam kehamilan akan dapat mempengaruhi kualitas kesehatan ibu dan janinnya. Kepatuhan dalam mengkonsumsi terapi obat yang diresepkan dipengaruhi oleh banyak hal, seperti usia, pengetahuan, pengalaman, persepsi, penjelasan aturan pakai obat, frekuensi kunjungan ANC dan lainnya[9].

Hasil survey awal terhadap 10 ibu hamil yang sudah melakukan 34 kali pemeriksaan ANC di klinik Bidan, diketahui bahwa 4 responden (40\%) masih tidak teratur dalam mengkonsumsi tablet vitamin dan mineral yang diberikan pada mereka. Alasan yang disampaikan adalah lupa, dan merasa malas mengkonsumsinya secara rutin, meskipun bidan sudah memberikan penjelasan bahwa obat harus dihabiskan. 1dari 4 responden yang tidak teratur dalam mengkonsumsi obat, mengalami Anemia ringan berdasarkan buku catatan KIA nya.

Berdasarkan masalah diatas, peneliti melakukan penelitian dengan judul "Determinan Kepatuhan Ibu Hamil dalam Mengkonsumsi Obat selama Kehamilan"

\section{Metode Penelitian}

Penelitian ini adalah deskriptif dengan Desain crosssectional, yaitu penelitian yang bertujuan untuk melihat gambaran atau mendeskripsikan suatu keadaan secara objektif. Dalam penelitian ini menggambarkan "Determinan Kepatuhan Ibu Hamil dalam Mengkonsumsi Obat selama Kehamilan"

Populasi penelitian adalah ibu hamil yang terdaftar sejak 20192020 di klinik bidan sebanyak 204 orang, pengambilan sampel secara Purposive sampling, dimana untuk menentukan sampel dengan menetapkan ciri-ciri khusus yang sesuai dengan tujuan penelitian sehingga diharapkan dapat menjawab permasalahan penelitian[12]. Sampel penelitian 
berjumlah 54 orang yang berkunjung ke klinik bidan dari Maret sampai Mei 2021 baik Primigravida dan Multigravida.

Instrument

penelitian menggunakan kuesioner dan catatan buku kohort dan KIA pasien yang ada di klinik Bidan, dengan mengindentifikasi kepatuhan ibu hamil dalam mengkonsumsi obat selama kehamilan.

\section{Hasil dan Pembahasan}

\section{Hasil Penelitian}

a. Data Umum

Hasil data terhadap karakteristik responden dalam penelitian ini dapat dilihat pada tabel sebagai berikut:

1) Umur

Tabel 1.1 Distribusi Frekuensi Karakteristik Responden

\begin{tabular}{|c|c|c|c|c|}
\hline No & Perilaku & $\mathrm{N}$ & Jumlah & Persentase $(\%)$ \\
\hline \multirow[t]{4}{*}{1} & Umur & 54 & & \\
\hline & $-\quad<20$ & & 1 & 1,8 \\
\hline & $-\quad 20-35$ & & 40 & 74,1 \\
\hline & $-\quad 35-45$ & & 13 & 24,1 \\
\hline \multirow[t]{4}{*}{2} & Pendidikan: & 54 & & \\
\hline & - $\quad$ Pendidikan Dasar & & 6 & 11,1 \\
\hline & - $\quad$ Pendidikan Menengah & & 32 & 59,3 \\
\hline & $\begin{array}{ll} & \text { Pendidikan Tinggi }\end{array}$ & & 16 & 29,6 \\
\hline \multirow[t]{3}{*}{3} & Pekerjaan: & 54 & & \\
\hline & - $\quad$ Bekerja & & 15 & 27,8 \\
\hline & - $\quad$ Tidak Bekerja & & 39 & 72,2 \\
\hline \multirow[t]{4}{*}{4} & Paritas & 54 & & \\
\hline & - $\quad$ Primi Gravida & & 17 & 31,5 \\
\hline & - $\quad$ Multi Gravida & & 32 & 59,3 \\
\hline & - Grande Multi Gravida & & 5 & 9,2 \\
\hline
\end{tabular}

Berdasarkan Tabel 1.1 dapat diketahui bahwa, mayoritas responden berdasarkan umur mayoritas 20-35 tahun sebanyak $\quad 40$ orang $(74,1 \%), \quad$ mayoritas berpendidikan Menengah sebanyak 32 orang $(59,3$ $\%$ ), mayoritas tidak bekerja sebanyak 39 orang $(72,2 \%)$, mayoritas multi gravida sebanyak 32 orang $(59,3 \%)$.

2) Sumber Informasi

Tabel 1.2 Distribusi Frekuensi Responden Berdasarkan Sumber Informasi tentang tatacara konsumsi obat

\begin{tabular}{llcc}
\hline No & Sumber Informasi & Frekuensi & $(\%)$ \\
\hline 1 & Tenaga kesehatan & 50 & 92,6 \\
2 & Non tenaga kesehatan & 4 & 7,4 \\
\hline & Total & 54100 & \\
\hline
\end{tabular}


Jurnal Kebidanan Harapan Ibu Pekalongan

Berdasarkan Tabel 1.2 dapat diketahui bahwa, mayoritas responden mendapatkan informasi cara mengkonsumsi obat dari tenaga kesehatan sebanyak 50 orang $(92,6 \%)$.

\section{b. Data Khusus}

Hasil analisis univariat terhadap Persepsi, Perilaku dan determinan Kepatuhan Ibu Hamil Dalam Mengkonsumsi Obat Selama Kehamilan pada responden dalam penelitian ini dapat dilihat pada tabel sebagai berikut:

1) Gambaran persepsi kepatuhan ibu terhadap penggunaan obat dalam kehamilan

Tabel 1.3 Distribusi Frekuensi Persepsi kepatuhan ibu hamil dalam mengkonsumsi obat

\begin{tabular}{|c|c|c|c|c|}
\hline No & Determinan kepatuhan & $\mathbf{N}$ & Jumlah & $\begin{array}{c}\text { Persentase } \\
(\%)\end{array}$ \\
\hline \multirow[t]{3}{*}{1} & $\begin{array}{l}\text { Persepsi Urgensi } \\
\text { mengkonsumsi obat saat } \\
\text { hamil }\end{array}$ & 54 & & \\
\hline & - $\quad$ Penting & & 48 & 88,9 \\
\hline & - $\quad$ Tidak Penting & & 6 & 11,1 \\
\hline \multirow[t]{3}{*}{2} & $\begin{array}{l}\text { Persepsi Kepatuhan minum } \\
\text { obat berdasarkan Kesesuaian } \\
\text { dosis }\end{array}$ & 54 & & \\
\hline & - $\quad$ Penting & & 40 & 74,1 \\
\hline & $\begin{array}{ll} & \text { Tidak Penting } \\
\end{array}$ & & 14 & 25,9 \\
\hline & 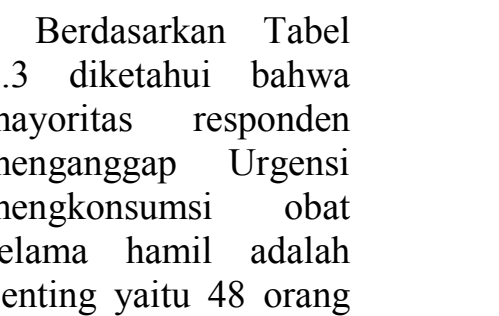 & & $\begin{array}{l}(88,9 \\
\text { bahw } \\
\text { respo } \\
\text { kepat } \\
\text { sesua } \\
\text { pentir } \\
\left(74,1^{\circ}\right.\end{array}$ & $\begin{array}{r}\text { diketahui } \\
\text { mayoritas } \\
\text { menganggap } \\
\text { minum obat } \\
\text { dosis adalah } \\
\text { aitu } 40 \text { orang }\end{array}$ \\
\hline
\end{tabular}

2) Gambaran Perilaku Kepatuhan ibu terhadap penggunaan obat dalam kehamilan

Tabel 1.4 Distribusi Frekuensi gambaran perilaku kepatuhan ibu hamil dalam mengkonsumsi obat

\begin{tabular}{ccccc}
\hline No & Determinan kepatuhan & N & Jumlah & $\begin{array}{c}\text { Persentase } \\
(\%)\end{array}$ \\
\hline 1 & Perilaku Kepatuhan minum obat & 54 & & \\
\hline & Patuh & & 29 & 53,7 \\
\hline & Tidak patuh & 25 & 46,3 \\
\hline
\end{tabular}


Jurnal Kebidanan Harapan Ibu Pekalongan

\author{
Berdasarkan Tabel \\ 1.4 diketahui bahwa \\ sebagian besar perilaku \\ kepatuhan minum obat
}

secara rutin responden adalah patuh yaitu 29 orang $(53,7 \%)$

3) Determinan compliance/kepatuhan dalam mengkonsumsi obat

Tabel 1.5 Distribusi Frekuensi Determinan compliance/kepatuhan dalam mengkonsumsi obat

\begin{tabular}{|c|c|c|c|c|}
\hline No & Determinan kepatuhan & $\mathbf{N}$ & Jumlah & Persentase (\%) \\
\hline \multirow[t]{3}{*}{1} & Penjelasan Nakes : & 54 & & \\
\hline & - Lengkap & & 34 & 79,1 \\
\hline & - $\quad$ Tidak Lengkap & & 20 & 20,9 \\
\hline \multirow[t]{3}{*}{2} & Pengetahuan: & 54 & & \\
\hline & - $\quad$ Baik & & 35 & 72,9 \\
\hline & - $\quad$ Kurang & & 13 & 27,1 \\
\hline \multirow[t]{3}{*}{3} & Sikap : & 54 & & \\
\hline & $-\quad$ Positif & & 44 & 68,8 \\
\hline & - $\quad$ Negatif & & 15 & 31,2 \\
\hline \multirow[t]{3}{*}{4} & $\begin{array}{l}\text { Kecemasan terhadap } \\
\text { efek samping obat }\end{array}$ & 54 & & \\
\hline & - $\quad$ Ada & & 33 & 68,8 \\
\hline & - $\quad$ Tidak ada & & 15 & 31,2 \\
\hline \multirow[t]{3}{*}{5} & $\begin{array}{l}\text { Frekuensi ANC delama } \\
\text { kehamilan }\end{array}$ & 54 & & \\
\hline & $-\quad \operatorname{Rutin}(\geq 4 x)$ & & 32 & 59,2 \\
\hline & $-\quad$ Jarang $(<4 \mathrm{x})$ & & 22 & 40,8 \\
\hline
\end{tabular}

Berdasarkan Tabel 1.5

diketahui bahwa mayoritas

Determinan

compliance/kepatuhan

dalam mengkonsumsi obat

berdasarkan penjelasan

nakes mayoritas lengkap

yaitu 34 orang $(79,1 \%)$,

berdasarkan Pengetahuan

mayoritas baik yaitu 35

orang (72,9\%).
Berdasarkan sikap mayoritas positif yaitu 44 orang $(68,8 \%)$, berdasarkan Kecemasan terhadap efek samping obat mayoritas ada yaitu 33 orang $(68,8 \%)$, berdasarkan frekuensi kunjungan ANC mayoritas rutin $(\geq 4 \mathrm{x})$ yaitu 32 orang $(59,2 \%)$.

\section{Pembahasan}

Kepatuhan ibu dalam mengkonsumsi obat-obat selama masa kehamilan akan membantu ibu dan janin sehat. Kepatuhan dikaitkan dengan keinginan dan kebutuhan pada seseorang, semakin tinggi keinginan dan kebutuhan seseorang terhadap suatu objek, maka nilai kepatuhannya juga meningkat. Ini tentunya dipengaruhi oleh pemahaman dan persepsi 
Jurnal Kebidanan Harapan Ibu Pekalongan

mereka terhadap objek yang mereka yakini, sehingga akan berkorelasi dengan perilaku yang ditampilkannya dalam mematuhi standar prosedur yang sudah ada[13].

Oleh karenanya kepatuhan atau ketidakpatuhan seseorang dalam mengkonsumsi obat-obatan dalam kehamilan dipengaruhi oleh banyak hal, seperti : umur, pendidikan, pekerjaan, persepsi, pengetahuan dan sikap, trauma atau kecemasan, dan lain-lain.Semakin ibu hamil patuh dalam mengkonsumsi obatobatan saat kehamilan, maka dapat mengurangi keluhannya serta mempengaruhi kesehatan ibu dan janin selama masa kehamilan[14].

\section{1) Persepsi ibu dalam mengkonsumsi obat masa kehamilan.}

Persepsi adalah merupakan ungkapan tentang suatu pengalaman yang diperoleh dari indra pengamatan terhadap suatu kondisi atau kejadian yang dialami, dengan mengorganisir hasil pengamatan tersebut dan dikembangkan dengan kenyataan lingkungan disekitar kita[15].

Pentingnya menghabiskan obat yang diberikan tenaga kesehatan baik dokter maupun bidan selama kehamilan akan meningkatkan kondisi kehamilan yang prima dan sehat. Mengkonsumsi obat yang banyak dan lama serta setiap hari, tentunya akan menimbulkan persepsi yang beragam bagi ibu hamil. Rasa mual dan bosan mengalihkan persepsi ibu dalam mengambil keputusan mengkonsumsi obatobatan[11].

Memahami sudut pandang pasien atau ibu hamil dalam memahami pentingnya atau
Urgensi mengkonsumsi obat dalam kehamilan serta Kepatuhan minum obat berdasarkan Kesesuaian dosis tentunya dipengaruhi oleh banyak hal, seperti pengetahuan mereka akan keutamaan merawat kehamilan dan janin dengan baik dan berkuliatas dalam kehamilan, pengalaman kehamilan lalu yang jarang melakukan pemeriksaan kehamilan dengan tanpa memiliki banyak keluhan kehamilan dan tidak ada komplikasi, akhirnya membangun persepsi dalam diri ibu bahwa kehamilan itu tidak harus dan tidak memerlukan asupan suplemen obat vitamin dan mineral, karena ibu merasa sudah merasa cukup mendapatkannya dari asupan makanan sehari-hari[10].

Sikap negatif serta protektif yang tinggi dari ibu dan pasangan akan dampak mengkonsumsi obat-obat kimiawi dalam kehamilan, menimbulkan kecemasan bagi ibu sehingga ibu akan menghindari mengkonsumsi obat-obatan kimiawi, dan beralih kepada asupan obat herbal dan alami yang diperoleh dipasaran. Rasa dan bau obat yang menyengat serta efek yang dihasilkan dari mengkonsumsi obat kimiawi seperti rasa mual dan mutah terutama pada obat yang mengandung iron/zat besi, juga membangun persepsi negative dan penerimaaan ibu dalam mengkonsumsi obatobatan dalam kehamilan. Alasan lainnya adalah malas mengkonsumsi obat secara rutin dan teratur setiap hari, serta bosan mengkonsumsi obat dalam jumlah banyak 
Jurnal Kebidanan Harapan Ibu Pekalongan

menjadikan ibu semakin kurang patuh dalam menghabiskan obat supplemen yang diberikan kepadanya[9].

Sudut pandang dan persepsi ibu yang salah dalam memahami tentang kebutuhan terhadap terapi obat-obatan dalam masa kehamilan mesti dikoreksi dan dijelaskan dengan bijak dan clear oleh tenaga kesehatan kepada ibu dan keluarga. Peran keluarga terutama suami sangat signifikan dalam sistem pengambilan keputusan ibu untuk mengkonsumsi suplemen obat vitamin dan mineral dalam masa kehamilan[14].

Mengupayakan pemahaman dan kesadaran ibu dalam pelaksanaan KIE/konseling yang tepat dan benar ketika pelayanan kesehatan akan membantu pemahaman pasien dalam mematuhi pola konsumsi obat-obatan[16]. Begitu juga saat pemeriksaan ANC provider kesehatan menjelaskan dengan baik setiap manfaat terapi obat, suplemen vitamin mineral yang diberikan untuknya dalam kehamilan akan mempengaruhi keputusan dan persepsi ibu dalam mengkonsumsi obatobatan yang aman selama kehamilan[4][14].

2) Perilaku kepatuhan ibu dalam mengkonsumsi obat masa kehamilan.

Perilaku kepatuhan dapat diartikan sebagai bagian habit dan kebiasaan yang sudah ada pada diri individu, dimana kepatuhan bermakna adanya keterikatan emosional dan kepercayaan yang kuat terhadap provider kesehatan oleh klien dalam melaksanakan anjuran, saran dan advice yang sudah disampaikan disaat pertemuan tatap muka mendapatkan pelayanan kesehatan[13]. Kejelasan informasi dan kemampuan untuk memberikan keyakinan dan penguatan kepada klien akan membuat rasa aware dan senang melakukan segala sesuatunya atas kesadaran diri klien itu sendiri[15].

Dalam pemberian obat pada ibu hamil, tentunya mengacu kepada standar operasional prosedur (SOP) farmakologik yang aman dan tepat. Ada banyak ketentuan dan penapisan yang dilakukan agar mampu memberikan obat yang sesuai untuk mereka[7]. Keluhan yang dialami selama kehamilan sebenarnya tidak selalu mesti dihilangkan dan dituntaskan dengan obat-obatan / farmakoterapy. Banyak terapi non farmakologik yang berkembang dewasa ini, sehingga mampu memberikan alternatif pilihan kepada ibu dalam menghilangkan keluhan ketidaknyamanan yang dihadapinya sehingga mampu memberikan kesempatan ibu mencari penanganan yang lain selain dari obat-obatan dan suplemen vitamin mineral dalam sediaan kimiawi. Dewasa ini banyak terapi acupuncture, hypnosis therapy, herbal alami, rempah dan jamu-jamuan, serta massage sedang trend dan menguasai pasar industry 4.0 ini, yang dikenal juga sebagai terapi complementer dan alternative (complementary and alternative medicine (CAM) therapies)[17].

Pengobatan komplementer dan alternatif sudah menjadi 
Jurnal Kebidanan Harapan Ibu Pekalongan

bagian praktik perawatan kesehatan dunia sebesar 65 hingga $80 \%$. Dimana perkiraan penggunaan ini tercatat semakin meningkat di negara maju seperti di Amerika Serikat saja sebanyak 72 juta orang menggunakan setidaknya satu terapi CAM setiap tahun dengan perkiraan 425 juta kunjungan penyedia alternatif setiap tahun. Terapi semacam itu digunakan di seluruh spektrum kondisi kesehatan yang luas, tetapi penggunaannya sangat penting selama kehamilan[17].

Sehingga seiring berkembangnya CAM terapy pada ibu hamil, maka semakin meningkat pula budaya masyarakat dalam mengurangi farmakologik terapi dalam mengatasi keluahan selama kehamilan, dan lebih memilih kembali ke alam (back to nature) [18]. Istilah back to nature yang membudidayakan perilaku dan habit masyarakat untuk mempopulerkan pemanfaaatn sumber daya alam dalam self healing atau penyembuhan diri, maka juga dapat mengubah mindset serta keteraturan ibu dalam memakan obat yang sudah diberikan tenaga kesehatan[19].

Hasil penelitian di Australia terhadap $211 \mathrm{ibu}$ hamil dalam penggunaan herbal prakonseptual dan dalam tiga trimester kehamilan maka didapatkan data Kebanyakan wanita(62\%) menggunakan suplemen vitamin atau mineral dan sediaan herbal dalam kehamilan. Folat (70\%), zat besi (38\%) dan multivitamin (27\%) adalahsuplemen vitamin dan mineral yang paling sering digunakan: Jahe $(20 \%)$ dan raspberry daun $(9 \%)$ merupakan sediaan herbal yang paling sering digunakan. Wanita mengandalkan nasihatdari teman dan kerabat dalam memutuskan untuk menggunakan sediaan herbal[20]. Penggunaan produk herbal tidak ada larangan dari pemerintah, tapi perlu kehatihatian ibu hamil dalam mengkonsumsinya. Dan lebih dianjurkan untuk berkonsultasi terlebih dahulu dengan provider kesehatannya[19].

Kemampuan provider kesehatan yang juga melihat hal terkini dengan up to date back to nature juga mesti ditambah, dikarenakan pergeseran paradigma dan cara pandang melihat suatu penyakit tidak semata-mata dapat dituntaskan hanya melalui obat kimiawi saja[19]. Provider kesehatan dapat mengkombinasikan anjuran dan advice kepada ibu agar menggunakan bahan-bahan obat herbal yang sudah di yakini dan diketahui secara ilmiah kandungannya memiliki kemampuan mengurangi gejala dan keluhan ketidaknyamanan yang dirasakan ibu seperti rebusan air jahe, dipercayai mengurangi mual muntah dan mengurangi nyeri serta mampu meningkatkan imunitas ibu[21][22], kunyit dan serai dipercaya mampu membantu meningkatkan vitalitas dan memperbaiki sel-sel tubuh serta menambah daya tahan tubuh[23], madu memberikan energy, semangat dan kaya antioksidan, membuat nyeyak tidur, baik untuk jantung dan membantu menurunkan kolesterol, serta mampu mengurangi batuk dan 
Jurnal Kebidanan Harapan Ibu Pekalongan

menyembuhkan

luka[18][24][25]. Meskipun

terdapat beberapa studi

penelitian yang menyatakan

masih banyak provider

kesehatan yang belum

menerima CAM $(83,7 \%)$, dan

memiliki persepsi negatif

tentang CAM, karena merasa

kurangnya bukti dalam

efektivitas

penyembuhannya[26].

Artinya disini provider kesehatan, tidak diharapkan menjadi skeptic dan menolak/reject dengan adanya manfaat lain bahan-bahan alami herbal dari alam, sehingga membantu ibu atau keluarga juga bisa mendapatkan pencerahan bahwa provider kesehatan yang ditemuinya open minded dan terbuka dengan ilmu lainnya, serta mampu memberikan penguatan kepada mereka dan tidak melarang mereka untuk menggunakan obat herbal dengan tetap berdampingan dalam pemakaian obat-obat kimiawi[27], yang tentunya tetap dibutuhkan dalam kehamilan seperti tablet zat besi/Fe, Calcium dan Vitamin Mineral lainnya yang mana dosisnya sudah aman dansesuai dengan kebutuhan ibu dalam menjaga keshetaan ibu dan janin dalam kehamilann ini[28].

Meskipun dalam keseharian ibu merasa sudah cukup dalam mengkonsumsi makanan yang bergizi dan menjaga pola asupan nutrisi yang sesuai, namun tetap proses penyerapan gizi yang dicerna tubuh tidaklah $100 \%$ akan diserap dan didistribusikan saat disaluran pencernaan ibu, ini karena ada faktor lain yang mempengaruhi dan menghambat proses penyerapan nilai gizi dari makanan seseorang seperti adanya interaksi makanan dengan makanan lainnya sehingga akan mengakibatkan tidak seluruh nilai gizi tersebut diterima tubuh seperti: apabila seseorang mengkonsumsi makanan bergizi dan seimbang dibarengi dengan air teh, air kopi, susu, atau soft drink, maka interaksi makanan seimbang yang sarat nilai gizi tersebut akan dihalangi penyerapannya oleh minuman tersebut[29]. Contoh: teh, mengandung tannine, yang akan mengurangi proses penyerapan makanan atau gizi diusus, sehingga jumlah nutrisi yang diedarkan kedalam darah menjadi tidak banyak, jika hal ini dilakukan oleh ibu hamil, maka bayi yang dilahirkannya akan mengalami berat badan lahir rendah atau berat badan lahir kecil, meskipun ibu diketahui memiliki nafsu makan yang besar dan banyak[30].

Teh, kopi, kafein, memiliki efek farmakologis yang kuat, efek pada janin yang belum lahir[31] konsumsi teh yang sering dalam kehamilan dapat memiliki risiko lebih tinggi dalam mengalami gestasi wight gain dan berat badan lahir rendah lebih tinggi dibandingkan jarang mengkonsumsi teh dalam kehamilan[32].

Oleh karena itu peran suplemen dan vitamin mineral juga dibutuhkan dalam menutupi kekurangan nilai gizi yang didapatkan ibu dari makanan sehari-harinya, dengan tetap Menjelaskan cara dan aturan pakai obat termasuk interaksi obat dengn obat 
Jurnal Kebidanan Harapan Ibu Pekalongan

lainnya serta interaksi obat dengan makanan[4].

Dalam tabel 1.4 penelitian ini dapat dilihat bahwa perilaku ibu yang patuh dalam mengkonsumsi obat dalam kehamilannya adalah 29 orang $(53,7 \%)$ dan yang tidak patuh 25 orang (46,3\%), meskipun pada tabel 1.3 dilihat hasil persepsi ibu hamil menganggap penting untuk mengkonsumsi obat selama hamil 48 orang $(88,9 \%)$ serta menganggap kepatuhan minum obat sesuai dosis adalah penting yaitu 40 orang $(74,1 \%)$, namun masih tinggi angka ketidak patuhan mereka dalam menghabiskan atau mengkonsumsi obat kehamilan yang sudah diberikan provider kesehatan kepada mereka.

Asumsi yang muncul dalam melihat data adalah bahwa masih terdapat hampir $1 / 2$ bagian sampel ibu hamil yang diteliti memiliki kasus yang sama, yaitu masih belum menghabiskan atau tidak mengkonsumsi obat yang diberikan provider kehatan untuk menjaga kehamilannya. Yang mana tentunya mereka akan memiliki banyak alasan dan jawaban kenapa tidak patuh dan menghabiskan obat suplemen vitamin dan mineral yang diberikan kepada mereka. Sehingga saat memberikan pelayanan ANC provider kesehatan harus memikirkan dan mencarikan solusi (problem solving) dalam mengatasi temuan masalah atau kondisi terkini dimasyarakat kita.

Dengan demikian sangat urgent sekali petugas kesehatan menilai kepatuhan ibu dalam mengkonsumsi obat dimasa kehamilan, serta diperlukan pengkajian ulang kepada ibu hamil saat ANC dengan mengajukan banyak pertanyaan kembali kepada ibu, apa alasan ibu menjadi patuh atau tidak patuh, sehingga provider akan memperoleh gambaran nyata dan real condition yang dialami pasien dilapangan[14]. Hal ini perlu dilakukan dengan follow up provider kesehatan pada ibu melalui pesan SMS, telepon, dan lainnya untuk mengingatkan mereka dalam mengkonsumsi obat-obat yang mereka terima[33]. Dikarenakan perubahan zaman dan era industi 4.0 ini, melalui media sosial dan kebebasan memperoleh informasi akan mempengaruhi pola fikir dan pemahaman seseorang dalam mengambil keputusan[34], terutamauntuk patuh atau tidak patuh dalam menghabiskan dan mengkonsumsi obat-obat kehamilan yang tersedia.

3) Determinan mengkonsumsi obat masa kehamilan

$\quad$ Dari hasil penelitian
diperoleh hasil mengkonsumsi obat berdasarkan penjelasan nakes mayoritas lengkap yaitu 34 orang $(79,1 \%)$, berdasarkan Pengetahuan mayoritas baik yaitu 35 orang $(72,9 \%)$. Berdasarkan sikap mayoritas positif yaitu 44 orang $(68,8 \%), \quad$ berdasarkan Kecemasan terhadap efek samping obat mayoritas ada yaitu 33 orang $(68,8 \%)$, berdasarkan frekuensi kunjungan ANC mayoritas rutin ( $\geq 4 \mathrm{x})$ yaitu 32 orang $(59,2 \%)$.

Faktor kepatuhan seseorang dalam melakukan anjuran, 
advice atau saran dari provider kesehatan dipengaruhi oleh banyak hal, yang mana ini akan berimbas pada kemampuan dia menjalani kondisi sehat sakit yang dialaminya[13]. Saat ibu hamil datang melakukan ANC akan selalu mendapatkan saran, penjelasan dan edukasi dalam menjaga kesehatan dan kehamilannya yang akan dilaluinya selama 9 bulan. Arahan dan anjuran mengkonsumsi obat-obat disesuaikan dengan keluhan dan masalah yang dirasakannya, serta usia kandungan yang dijalaninya. Bidan dan dokter akan selalu berusaha bijak dan tepat dalam mengatasi gangguan ketidaknyamanan yang dirasakan memang perlu penangananganan melaului terapi farmakologik atau obatobatan[9].

Kriteria obat yang diberikan pada ibu hamil adalah, sesuai kebutuhan, tidak banyak, aman dan dosis yang tepat. Biasanya pemberian obat-obatan dalam kehamilan lebih banyak bersifat preventif therapy, seperti anti anemia, mencegah kekuarangan kalsium, meningkatkan imunitas dan jumlah vitamin mineral tubuh, pencegahan hipertensi, dan lainlain. Jika untuk promotif therapy lebih banyak diresepkan dokter seperti anti emetic, obat penurun hipertensi[1]dan lainnya.

Faktor penjelasan provider terhadap obat-obatan tentang cara pakai, frekuensi, bagaimana interaksi obat, dan lainnya dapat menentukan keputusan pasien dalam mengkonsumsi obat dengan rutin[13], tentunya akan mengurangi atau menghilangkan kecemasan ibu dalam mengkonsusmi obat yang aman selama kehamilan. Kecemasan yang dirasakan ibu seperti apakah obat kimia ini aman untuk janinnya, apakah memiliki efek kecatatan pada janin yang dikandungnya, dan apakah obat ini membahayakan kesehatan jantung dan organ tubuh lainnya jika dikonsumsi lama kehamilan[28].

Ada beberapa hal yang menjadi faktor penentu pasien dalam mematuhi anjuran dalam mengkonsumsi obat yang diberikannya, yaitu: jumlah obat, lama pemberian, kejelasan dalam aturan pakai, efek samping pemakaian dan manfaat obat bagi pasien[13]. Hal ini terlihat jelas dari data penelitian ini bahwa mayoritas responden mendapatkan informasi cara mengkonsumsi obat dari tenaga kesehatan sebanyak 50 orang $(92,6 \%)$.

Faktor pengetahuan dan pemahaman ibu hamil akan pentingnya obat yang diberikan dalam kehamilan, sangat didukung oleh adanya kemudahan akses dalam mendapatkan informasi tentang perawatan diri dalam masa kehamilan, semakin baik pengetahuannya semakin baik perilaku kepatuhannya dalam menerima dan menghabiskan obat yang diberikan kepadanya[9].

Sikap dan persepsi yang baik dalam menerima pengetahuan baru dan memahami pentingnya obat kehamilan yang diberikan adalah untuk menambah vitalitas dan meningkatkan kesehatan janin serta stamina tubuhnya, sehingga memudahkan ibu dalam 
Jurnal Kebidanan Harapan Ibu Pekalongan

beraktivitas sehari-hari, maka tentunya ini adalah modal yang baik membuat ibu merasa yakin dan percaya keapada provider kesehatan saat ANC dalam mematuhi atauran pakai obatobat yang tersedia[15].

Kunjungan ANC yang rutin akan membantu meningkatkan pemahaman dan wawasan ibu dalam mengenali komplikasi dan bahaya yang mengancam kesehatan ibu dan janinnya, sehingga dipandang perlu untuk mengembangkan kegiatan KIE / konseling yang berkualitas pada ibu dengan metode pendekatan interpersonal dalam membentuk hubungan saling percaya antara provider kesehatan dengan pasiennya, sehingga kunjungan ANC tidak sebatas hanya melakukan pemeriksaan kondisi janin saja, namun juga meupakan sarana komunikasi dua arah dan banyak arah antara provider kesehatan, ibu dan keluarga[4].

\section{Kesimpulan}

Hasil penelitian Determinan Kepatuhan Ibu Hamil dalam Mengkonsumsi Obat Selama Kehamilan didapatkan hasil 29 responden $(53,7 \%)$ patuh dalam mengkonsumsi obat dalam kehamilan, berdasarkan faktor penjelasan nakes mayoritas lengkap yaitu 34 orang $(79,1 \%)$, berdasarkan Pengetahuan mayoritas baik yaitu 35 orang $(72,9 \%)$. Berdasarkan sikap mayoritas positif yaitu 44 orang (68,8\%), berdasarkan Kecemasan terhadap efek samping obat mayoritas ada yaitu 33 orang $(68,8 \%)$, berdasarkan frekuensi kunjungan ANC mayoritas rutin ( $\geq 4 \mathrm{x})$ yaitu 32 orang $(59,2 \%)$. Diharapkan agar ibu hamil dapat memperhatikan aturan dan tata cara mengkonsumsi obat selama kehamilan ini dan provider kesehatan dapat mengkaji ulang perilaku ketidakpatuhan ibu hamil dalam mengkonsumsi obat yang sudah diberikan kepada mereka.

\section{Daftar Pustaka}

[1] WHO, Giudelines for the identification and management of Substance Use and substance use disoerders in pregnancy, 139th-84th ed. Routledge Handb Deviance, 2018.

[2] A. Agarwal and O. Singh, "Drugs in Pregnancy: an Update," J. South Asian Fed. Obstet. Gynaecol., vol. 6, no. 3, pp. 0-0, 2014, doi: 10.5005/jsafog-6-3-vii.

[3] D. G. Carroll et al., "Drugs in Pregnancy."

[4] WHO, "WHO recommendation on ANC for a positive pregnancy experience," e-book, pp. 1172, 2016.

[5] Substance Abuse and Mental Health Services

Administration, Clinical guidance for treating pregnant and parenting women with opioid use disorder and their infants, vol. (SMA), no. 18-5054. 2018.

[6] The Royal College of Obstetricians and Gynaecologist, "The Management of Nausea and Vomiting of Pregnancy and Hyperemesis Gravidarum: Green-top Guideline No. 69," RCOG Green-top Guidel. No. 69, no. 1, pp. 1-27, 2016. 
Jurnal Kebidanan Harapan Ibu Pekalongan

[7] F. O. KELSEY, "Drugs in Pregnancy.," Minn. Med., vol. 48, pp. 175-180, 1965.

[8] Nottinghamshire area prescribing committee, "Primary Care Management of Nausea and Vomiting In Early Pregnancy," Drug Ther. Bull., vol. 57, no. 4, p. 52, 2019, doi: 10.1136/dtb.2019.000003.

[9] Eka Yuli Handayani, "HUBUNGAN

KEPATUHAN

MENGKONSUMSI

TABLET Fe TERHADAP KEJADIAN ANEMIA PADA IBU HAMIL TRIMESTER III DI PUSKESMAS RAMBAH HILIR I KABUPATEN ROKAN HULU," Matern. Neonatal, vol. 03, no. 02, pp. 125-131, 2020.

[10] D. T. U. Dr. T. Manmohan, Dr. G. Sreenivas, Dr. V.V. Sastry, Dr. E. Sudha Rani, Dr. K. Indira, "Review Article: Drug Compliance and adherence to treathment," vol. 1, pp. 142159, 2012.

[11] A. S. Eldalo, N. Siraj, and Y. Ma, "Pregnant Women's Awareness and Perception About Medicines," Lat. Am. J. Pharm., vol. 34, no. 5, pp. 869-874, 2015.

[12] D. Jajoo and S. K. Malu, "Resarch Methodology," A Study Buy. Decis. Process Malls, pp. 49-64, 2014.

[13] R. Düsing, K. Lottermoser, and T. Mengden, "Compliance with drug therapy - New answers to an old question," Nephrol. Dial. Transplant., vol. 16, no. 7, pp. 1317-1321, 2001, doi: 10.1093/ndt/16.7.1317.

[14] Haryadi and A. Jasda, "The relationship of pregnant women knowledge About iron deficiency Anemia and the role of family In Compliance in consuming $\mathrm{Fe}$ tablets in health center," $J$. Ners dan Kebidanan Indones., vol. 6, no. 1, p. 49, 2019, doi: 10.21927/jnki.2018.6(1).4958.

[15] J. Lin, G. E. Sklar, V. M. Sen $\mathrm{Oh}$, and S. C. Li, "Factors affecting therapeutic compliance: A review from the patient's perspective," Ther. Clin. Risk Manag., vol. 4, no. 1, pp. 269-286, 2008, doi: $10.2147 /$ tcrm.s1458.

[16] K. Blum et al., "Systematic evaluation of 'compliance' to prescribed treatment medications and 'abstinence' from psychoactive drug abuse in chemical dependence programs: Data from the Comprehensive Analysis of Reported Drugs," PLoS One, vol. 9, no. 9, pp. 1-10, 2014, doi: 10.1371/journal.pone. 010427 5. 
Jurnal Kebidanan Harapan Ibu Pekalongan

[17] M. Hastings-Tolsma, "Decision-making for use of complementary and alternative therapies by pregnant women and nurse midwives during pregnancy: An exploratory qualitative study," Int. J. Nurs. Midwifery, vol. 5, no. 4, pp. 76-89, 2013, doi: 10.5897/ijnm2013.0100.

[18] I. K. Yulina, "Back to Nature: Kemajuan atau Kemunduran," Mangifera $E d u$, vol. 2, no. 1, pp. 20-31, 2017, doi: 10.31943/mangiferaedu.v2i1. 15.

[19] T. H. S. Sudirman, "Pemanfaatan Pelayanan Pengobatan Tradisional (Batra) Sebagai Role Model Back To Nature Medicine di Masa Datang," ARSY J. Apl. Ris. Kpd. ..., vol. 1, no. 1, pp. 45-50, 2020.

[20] M. Health, Food and Nutrition Guidelines for Healthy Pregnant and Breastfeeding Women A background paper. .

[21] M. Thomson, R. Corbin, and L. Leung, "Effects of ginger for nausea and vomiting in early pregnancy: A metaanalysis," J. Am. Board Fam. Med., vol. 27, no. 1, pp. 115122, 2014, doi: 10.3122/jabfm.2014.01.1301 67.

[22] A. J. Lindblad and S. Koppula, "Ginger for nausea and vomiting of pregnancy," Can. Fam. Physician, vol. 62 , no. 2 , p. 145 , 2016, doi: $10.1097 / 00006250$ 200104000-00017.
[23] G. Tossetta, S. Fantone, S. R. Giannubilo, and D. Marzioni, "The Multifaced Actions of Curcumin in Pregnancy Outcome 2. Curcumin Effects on Fertilization and Fetal Developmen and conditioned by the microenvironment [20]. For this reas fect on oocyte maturation, fertilization and development of $\mathrm{t}$ different conce" pp. 1-20, 2021.

[24] S. Bogdanov, "Honey as nutrient and functional food," Proteins, vol. 1100, no. January, pp. 1400-2700, 2012.

[25] P. Wulandari, "Honey To Prevent Iron Deficiency Anemia in Pregnancy" $J$ Major, vol. 4, p. 90, 2015.

[26] C. K. Tan, A. Alip, V. P. Jye, and F. Ismail, "354P Knowledge, perception, and attitude of oncology-related healthcare providers on complementary and alternative medicine (CAM)" Ann. Oncol., vol. 31, p. S1377, 2020, doi: 10.1016/j.annonc.2020.10.34 8.

[27] A. Khan et al., "Awareness, Self-Use, Perceptions, Beliefs, and Attitudes toward Complementary and Alternative Medicines (CAM) among Health Professional Students in King Saud bin Abdulaziz University for Health Sciences Jeddah, Saudi Arabia" Evidence-based Complement. Altern. Med., vol. 2020, 2020, doi: $10.1155 / 2020 / 7872819$. 
Jurnal Kebidanan Harapan Ibu Pekalongan

[28] L. A. J. Barnes, L. Barclay, K. McCaffery, and P. Aslani, "Factors influencing women's decision-making regarding complementary medicine product use in pregnancy and lactation" BMC Pregnancy Childbirth, vol. 19, no. 1, pp. 1-14, 2019, doi: $10.1186 / \mathrm{s} 12884-$ 019-2396-2.

[29] D. Plećaš, S. Plešinac, and O. K. Vučinić, "Nutrition in pregnancy: Basic principles and recommendations" Srp. Arh. Celok. Lek., vol. 142, no. 1-2, pp. 125-130, 2014, doi:

10.2298/SARH1402125P.

[30] A. Fajrina, J. Junuarty, and S. Sabirin, "Penetapan kadar tanin pada teh celup yang beredar dipasaran secara spektrofotometri uv-vis" $J$. Farm. Higea, vol. 8, no. 2, pp. 133-142, 2016.

[31] T. Van Der Hoeven, J. L. Browne, C. S. P. M. Uiterwaal, C. K. Van Der Ent, D. E. Grobbee, and G. W. Dalmeijer, "Antenatal coffee and tea consumption and the effect on birth outcome and hypertensive pregnancy disorders" PLoS One, vol. 12 , no. 5 , pp. $1-12$, 2017, doi: 10.1371/journal.pone. 017761 9.
[32] S. K. Jasim, H. Al-Momen, and A. K. Alqurishi, "Effects of excessive tea consumption on pregnancy weight gain and neonatal birth weight" Obstet. Gynecol. Sci., vol. 64, no. 1, pp. 34-41, 2021, doi: 10.5468/OGS.20157.

[33] P. A. Dewi and D. Ayuningtyas, "Effectiveness of Text Message Reminder for Improving Compliance to Tuberculosis Drug Consumption: A Systematic Review" pp. 342-342, 2019, doi:

10.26911/the6thicph.05.07.

[34] M. Yusmita, Z. Larisu, and Saidin, "Pemanfaatan WhatsApp Messenger Sebagai Media Komunikasi Antar Pribadi Mahasiswa Ilmu Komunikasi *Mei Yusmita ** Dr. Zulfiah Larisu, S.Sos, M.Si., *** Saidin, S.Ip, M.Si.," pp. 112, 2014. 